\title{
Epidermal Growth Factor Receptor Family and its Role in Gastric Cancer
}

\author{
Chiara Arienti, Sara Pignatta and Anna Tesei ${ }^{*}$ \\ Biosciences Laboratory, Istituto Scientifico Romagnolo per lo Studio e la Cura dei Tumori (IRST) IRCCS, Meldola, Italy
}

Despite the gradual decrease in incidence, gastric cancer is still the third leading cause of cancer death worldwide. Although chemotherapy enhances overall survival and quality of life in advanced disease, the median overall survival is $<12$ months. In recent years, the human epidermal growth factor receptor (ErbB) family has been extensively investigated in gastric cancer. The ErbB family is composed of four closely-related members: ErbB-1 (HER1 or epidermal growth factor receptor, EGFR), ErbB-2 (HER2), ErbB-3 (HER3), and ErbB-4 (HER4), all of which play a critical role in regulating cell growth, proliferation and migration of tumors. It is well known that gastric cancer overexpresses HER in a heterogeneous pattern, especially EGFR, and HER2. HER3 is another important member of the ErbB family that preferentially activates the phosphatidylinositol 3-kinase (PI3K) pathway. Furthermore, its heterodimerization with HER2 seems fundamental for steering HER2-overexpressing breast cancer tumor growth. Less is known about the impact of HER4 on gastric cancer. Improved survival from the use of trastuzumab has paved the way for ErbB receptor family-targeted treatments in gastric cancer. However,

OPEN ACCESS

Edited by:

Lin Chen,

PLA General Hospital, China

Reviewed by:

Guglielmina Nadia Ranzani, University of Pavia, Italy

Savio George Barreto,

Medanta the Medicity, India

*Correspondence:

Anna Tesei

anna.tesei@irst.emr.it

Specialty section:

This article was submitted to

Gastrointestinal Cancers,

a section of the journal

Frontiers in Oncology

Received: 09 September 2019 Accepted: 11 November 2019 Published: 26 November 2019

Citation:

Arienti C, Pignatta S and Tesei A (2019) Epidermal Growth Factor

Receptor Family and its Role in Gastric Cancer. Front. Oncol. 9:1308. doi: 10.3389/fonc.2019.01308 unlike trastuzumab, ErbB receptor-targeted drugs have not consistently maintained the encouraging results obtained in preclinical and early clinical trials. This may be attributable to the intrinsic heterogeneity of gastric cancer and/or to the lack of standardized test quality for established biomarkers used to evaluate these biological targets. This review presents an overview of the most recent clinical studies on agents targeting the ErbB family in gastric cancer.

Keywords: HER2, EGFR, tyrosine kinase inhibitor, targeted therapy, gastric cancer, clinical trial

\section{INTRODUCTION}

Gastric cancer is the fifth most common malignancy and the third leading cause of cancer death worldwide (1). In Europe, it is the fifth most common cancer in both sexes, accounting for around $23 \%$ of all cancers. The annual incidence is $20 / 100,000$ for men and $9 / 100,000$ for women, resulting in $\sim 107,000$ deaths annually (2). There is a distinct geographic variability in gastric cancer, the highest rates being observed in East Asia, South America and Eastern Europe, and the lowest rates in the U.S. and Western Europe (3).

\section{TREATMENT OPTIONS FOR GASTRIC CANCER}

\section{Surgery}

Surgical resection remains the primary treatment for all patients with regionally confined disease, the extent of the intervention depending on the site of the tumor. Total gastrectomy is usually recommended for proximal tumors but is not considered superior to subtotal gastrectomy in terms of survival in distal gastric cancer $(4,5)$. 
Patients with superficial early gastric cancer (T1a) are candidates for endoscopic mucosal resection (EMR). T1a is defined as adenocarcinomas confined to the mucosa, $<2 \mathrm{~cm}$ in diameter, low-moderate differentiation, no evidence of ulcer, and with no lymphovascular involvement $(6,7)$. The extent of lymph node dissection is hotly debated and studies have failed to confirm a survival benefit of D1 dissection (dissection of the perigastric nodes) over D2 dissection (dissection of perigastric nodes and nodes along the left gastric, hepatic, celiac, and splenic arteries). D2 dissection is associated with fewer locoregional recurrences and gastric cancer-related death, but also with higher rates of morbidity and mortality. A modified (spleenpreserving) D2 dissection is considered standard treatment in many hospitals. The addition of para-aortic dissection to D2 dissection does not improve survival (8-10).

Surgical resection represents standard curative gastric cancer treatment (11), but around $25 \%$ of patients have unresectable tumors at diagnosis due to the presence of metastatic disease.

\section{Chemotherapy or Chemoradiation}

Chemotherapy is considered a feasible option in patients with metastases but good functional status and an acceptable life expectancy $(12,13)$. First-line treatment for metastatic disease includes a combination of a platinum compound and fluorouracil. The addition of another agent such as an anthracycline (e.g., epirubicin) in Europe (ECF = epirubicin, cisplatin, and fluorouracil) or a taxane (e.g., docetaxel) in the U.S. (DCF = docetaxel, cisplatin, and fluorouracil) is common practice (14-16). Other studies have demonstrated that fluorouracil can be substituted by capecitabine, and cisplatin by oxaliplatin $(17,18)$. Substituting oxaliplatin for cisplatin is associated with lower toxicity $(17,19)$. Recent trials have used EOX (epirubicin, oxaliplatin, and fluorouracil) and FLO (fluorouracil, calcium folinate [leucovorin], and oxaliplatin) $(17,18)$.

Overall survival is higher in patients with locally advanced gastric cancer treated with chemoradiation than in those treated with radiation alone $(20,21)$. Adverse effects of radiation include nausea, vomiting (patients may need to be pre-treated with antiemetics prior to radiation), weight loss, and diarrhea. Less commonly, radiation can cause small bowel obstruction, liver damage, and kidney damage.

\section{Perioperative Chemoradiation or Chemotherapy}

In patients with pathologic stage II-IIIC or any $\mathrm{T}, \mathrm{N}+$ disease or $\mathrm{R} 1$ resection, postoperative radiation combined with adjuvant fluorouracil has been shown to improve overall survival (22, 23). Postoperative chemoradiation consists of one cycle of fluorouracil (with or without calcium folinate) given prior to radiation, followed by two cycles after radiation. During radiation, patients receive fluorouracil on the first 4 and last 3 days of radiation. Preoperative chemoradiation consisting of radiotherapy and fluorouracil (or fluorouracil and paclitaxel) is used to induce tumor downstaging and increase respectability (24). Another option is adjuvant chemotherapy, which improves survival in patients undergoing curative resection $(25,26)$. In patients with stage II or higher gastric cancer, perioperative chemotherapy with ECF (epirubicin, cisplatin, and fluorouracil) has been shown to improve overall survival (27), although results of trials of postoperative chemotherapy vary substantially. In fact, in the U.S., postoperative studies have failed to demonstrate any benefit, whereas Japanese data favor adjuvant chemotherapy after D2 dissection (28).

Despite the significant improvements obtained from chemotherapy and chemoradiotherapy regimens, the prognosis for patients with advanced gastric cancer remains poor, with a median survival of $<12$ months, mainly because the disease is already advanced when the initial diagnosis is made. In recent years, substantially longer survival and significantly improved quality of life of gastric cancer patients have been obtained using targeted therapies $(29,30)$. In particular, molecular drugs targeting the human epidermal growth factor receptor (ErbB) family have been amply investigated and are currently under evaluation in several phase III clinical trials.

\section{ErbB Family}

The epidermal growth factor receptor family consists of four related receptor tyrosine kinases: EGFR (ErbB1, HER1), ErbB2 (HER2, neu in rodents), ErbB3 (HER3), and ErbB4 (HER4) (31). Although the human ErbB genes are found on four different chromosomes, all members share a common structure, including an extracellular domain, lipophilic transmembrane region, intracellular domain containing tyrosine kinase, and a carboxy-terminal region. EGFR, the first member of this receptor family to be discovered (32), was also the first receptor for which evidence emerged of a relationship between receptor overexpression and cancer (33). Several alterations in ErbB family members were subsequently found to be correlated with the development and progression of numerous human cancers, e.g., non-small cell lung cancer (34), breast (35), colorectal (36), laryngeal (37), esophageal (38), ovarian (39), and prostate cancer (40), and melanoma (41) as a result of their pivotal role in signal transduction. In particular, the ErbB signaling network consists of several overlapping and interconnected modules including the phosphatidylinositol 3-kinase (PI3K)/Akt (PKB) pathway, the Ras/Raf/MEK/ERK1/2 pathway, and the phospholipase C (PLC $\gamma$ ) pathway. The PI3K/Akt pathway plays an important role in mediating cell survival, while the Ras/ERK1/2 and PLC $\gamma$ pathways are involved in cell proliferation (42). These and other ErbB signaling modules influence angiogenesis, cell adhesion, cell motility, development, and organogenesis (43).

The ligands that bind to each monomeric receptor are shown in Table 1. Notably, 7 growth factors bind to EGFR, none binds to HER2, 2 bind to HER3, and 7 bind to HER4. The 4 ErbB family members form 28 homo- and heterodimers. The 11 growth factors in the EGF-like family and the 28 dimers make 614 receptor combinations possible. The binding of ligands to the extracellular domain of EGFR, HER3, and HER4 leads to the formation of kinase-active hetero-oligomers (31). The activation of HER2 and EGFR results in transphosphorylation of the ErbB dimer partner, stimulating intracellular pathways including RAS/RAF/MEK/ ERK, PI3K/AKT/TOR, Src kinases, and STAT transcription factors (42). In particular, HER2 does not bind 
TABLE 1 | Pattern of ErbB receptor binding

\begin{tabular}{|c|c|c|c|c|}
\hline \multirow[t]{2}{*}{ Growth factor } & \multicolumn{4}{|c|}{ Receptor binding } \\
\hline & EGFR & HER2 & HER3 & HER4 \\
\hline $\begin{array}{l}\text { Epidermal growth factor } \\
\text { (EGF) }\end{array}$ & + & - & - & - \\
\hline Epiregulin & + & - & - & + \\
\hline Epigen & + & - & - & - \\
\hline Betacellulin & + & - & - & + \\
\hline $\begin{array}{l}\text { Heparin-binding } \\
\text { epidermal growth factor } \\
\text { (HB-EGF) }\end{array}$ & + & - & - & + \\
\hline $\begin{array}{l}\text { Transforming growth } \\
\text { factor- } \alpha\end{array}$ & + & - & - & - \\
\hline Amphiregulin & + & - & - & - \\
\hline Neuregulin 1 & - & - & + & + \\
\hline Neuregulin 2 & - & - & + & + \\
\hline Neuregulin 3 & - & - & - & + \\
\hline Neuregulin 4 & - & - & - & + \\
\hline
\end{tabular}

directly to any ErbB ligand but rather is fixed in a conformation resembling a ligand-activated state, favoring dimerization (44, 45). In fact, although EGFR, HER3, and HER4 are activated by ligand binding, the specific ligands to which HER2 binds have still not been identified (46). However, aberrant HER2 activity and HER2 receptor activation results in receptor dimerization (e.g., HER2/HER3), which triggers a complex signal transduction cascade, modulating survival, proliferation, mobility and cancer cell invasiveness (47).

The HER3 receptor, despite showing weaker kinase activity than that of its ErbB co-receptors, plays a key role in promoting cell survival (48). HER3 binds ATP and catalyzes autophosphorylation. After transphosphorylation by another ErbB family member, HER3 acts as an efficient phosphotyrosine scaffold, leading to strong downstream signaling activation. In particular, HER3 is a powerful inducer of the PI3K/Akt pathway through six consensus phosphor-tyrosine sites on its C-terminal tail which bind the PI3K p85 subunit (49-51). Furthermore, in HER2-driven tumors, the HER2-HER3 dimer has proven essential for tumor formation and maintenance $(52,53)$. In particular, the role of HER3 in resistance to HER2-targeted therapy in this tumor subtype has been underlined in numerous studies showing that HER3 upregulation may induce resistance to several signaling inhibitors designed to directly or indirectly antagonize activated PI3K signaling. Furthermore, although the HER2-HER3 dimer is the strongest HER family dimer, HER3 has been seen to dimerize with EGFR and with non-ErbB family members, including c-MET $(54,55)$.

HER4 is a unique cell surface receptor that mediates the activity of transmembrane tyrosine kinase. Unlike other ErbB receptors, there is evidence that HER4 is characterized by antiproliferative and pro-apoptotic activity $(56,57)$. In cell line experiments when HER2-positive cancer cells were transfected to overexpress HER4, researchers observed reduced proliferation and increased apoptosis (56), suggesting that
HER4 antagonizes HER2 signaling activity (58). Four HER4 receptor isoforms resulting from the alternative splicing of HER4 mRNA have been described (JMa or JMb, Cyt1 or Cyt2) (59). The JMa isoform comprises an extracellular proteolytic site cleaved by the metalloproteinase tumor necrosis factoralpha converting enzyme (TACE) (60). After cleavage, the transmembrane cleavage product $(\mathrm{m} 80)$ undergoes a second intramembrane-secretase cleavage that releases a soluble HER4 intracellular domain (4ICD) into the cytoplasm (61). The 4ICD either remains in the cytosol or translocates to the nucleus. The HER4 intracellular domain is characterized by multiple biological activities and cellular responses including differentiation, pro-apoptotic pathway activation, cell cycle arrest, transcription modulation through the formation of complexes with transcription factors, and cell proliferation. These responses are associated with 4ICD localization in different cell compartments (62). Nuclear 4ICD has been found to be a powerful ER co-activator, interacting directly with ligandassociated ER and promoting ER-positive breast tumor cell proliferation (63). It has also been seen that 4ICD accumulates within the mitochondria, promoting tumor cell apoptosis through the activity of the cell-killing $\mathrm{BH} 3$ domain (57). The manipulation of 4ICD cell localization is thus a potentially effective therapeutic strategy.

\section{ErbB Expression and Gastric Cancer}

EGFR is overexpressed in $27 \%-64 \%$ of gastric tumors $(64,65)$ and its role as an oncogene in this malignancy is well-known. However, there is no general consensus on the prognostic value of EGFR status in gastric cancer patients. Some authors suggest that high gene amplification is associated with poor outcome $(66,67)$, while others sustain the opposite (68). Moreover, a 2013 metaanalysis comparing the results obtained in 5 different studies on a total of 1,600 patients concluded that EGFR expression is not an independent predictor of survival in gastric cancer (69).

HER2 overexpression/amplification varies considerably among studies (6 to $30 \%$ ) and is partly attributable to variability in histologic subtype and primary tumor localization (70). The highest expression rates have been seen in intestinal type tumors located proximally to the gastroesophageal junction (71). Studies on gastric cancer have obtained inconsistent results on the prognostic role of HER2. Although the majority reported that positivity to HER2 is associated with a poor prognosis $(72,73)$, some did not observe an association between HER2 status and outcome (74) or a longer median overall survival in patients with HER2-positive gastric cancer compared with those with HER2negative tumors $(74,75)$. Although the correlation between HER2 status and gastric cancer prognosis is still open to debate, HER2 protein expression or gene amplification is currently used as a biomarker for targeted therapy in this tumor (71-76).

HER3 and HER4, like EGFR and HER2, have also been found to be expressed in $20.7 \%$ and $13.3 \%$ of gastric cancers, respectively (77). A correlation between high HER3 expression and poor survival has been described in several studies (78-80). Conversely, the few studies performed to date on HER4 in gastric cancer have not clarified its role as a prognostic marker. A recent work by He et al. highlighted an association between high HER4 
TABLE 2 | Evaluation of immunostaining for EGFR and HER2.

\begin{tabular}{|c|c|c|c|}
\hline Classification & IHC Score & EGFR & HER2 \\
\hline Negative & 0 & $\begin{array}{l}\text { No staining or } \\
\text { background type } \\
\text { staining }\end{array}$ & No staining or $<10 \%$ \\
\hline Negative & $1+$ & $\begin{array}{l}\text { Discontinuous } \\
\text { membrane staining; } \\
>10 \%\end{array}$ & $\begin{array}{l}\text { Faint/barely } \\
\text { perceptible > 10\% }\end{array}$ \\
\hline Equivocal & $2+$ & - & $\begin{array}{l}\text { Weak to moderate; } \\
\text { complete or } \\
\text { basolateral membrane } \\
\text { staining; }>10 \%\end{array}$ \\
\hline Positive & $2+$ & $\begin{array}{l}\text { Weak to moderate; } \\
>10 \%\end{array}$ & $\mathrm{IHC} 2+$ and $\mathrm{FISH}+$ \\
\hline Positive & $3+$ & $\begin{array}{l}\text { Moderate to strong; } \\
\text { complete membrane } \\
\text { staining; >10\% }\end{array}$ & $\begin{array}{l}\text { Moderate to strong; } \\
\text { complete or } \\
\text { basolateral membrane } \\
\text { staining; }>10 \%\end{array}$ \\
\hline
\end{tabular}

IHC, immunohistochemistry; FISH, fluorescence in situ hybridization.

expression and TNM (Tumor-Nodes-Metastasis) but not HER4 overexpression and survival (77).

\section{ErbB Testing in Gastric Cancer}

Several studies have been conducted on EGFR expression in gastric cancer, and variations in the reported expression of the receptor may be due to differences in sample size, detection methods or evaluation standards used. Some authors observed that EGFR was not expressed in normal gastric mucosa but highly expressed in gastric cancer tissue, concluding that EGFR expression could be related to EGFR gene amplification and mutation, continuous EGFR activation, and activation of an abnormal signal transduction pathway. However, it has yet to be proven that high EGFR expression in gastric cancer is a result of gene amplification or mutation.

EGFR expression can be detected in several ways, e.g., by genomic assays that quantify the number of EGFR gene copies or number of cell surface receptors (Table 2). Genomic assays include:

1. Fluorescence in situ hybridization (FISH) and chromogenic in situ hybridization (CISH), both of which measure EGFR gene amplification by quantifying gene copy number (66);

2. Immunohistochemistry (IHC), which measures the number of cell receptors, thus enabling quantification of receptor overexpression (81).

The widespread use of trastuzumab in breast cancer underlines the importance of high-quality HER2 testing and scoring to ensure the accurate identification of patients most likely to benefit from this targeted therapy. HER2 testing in gastric cancer differs from that of breast cancer because of the inherent differences in tumor biology, i.e., HER2 heterogeneity (focal staining) and incomplete membrane staining are more frequent in gastric cancer. These observations have led to the development and standardization of gastric cancer-specific HER2 testing protocols which must be adhered. HER2 status is mainly assessed by
IHC (which measures the number of HER2 receptors on the cell surface, thus detecting receptor overexpression) or FISH (which detects gene amplification by measuring the number of HER2 gene copies in tumor cell nuclei) using biopsy or surgical specimens (82). However, following the results obtained in the ToGA trial, trastuzumab was approved for use in HER2-positive gastric cancer defined as IHC $3+$ or, alternatively, in FISHpositive gastric cancer in the USA and Japan. Of note, in Europe HER2-positive gastric cancer is defined as IHC $3+$ or IHC $2+$ plus positive FISH (83) (Table 2).

Unlike EGFR and HER2, there is no standardized method for assessing HER3 status. The most widely used methods are IHC, FISH and quantitative reverse transcription polymerase chain reaction (RT-PCR), which evaluates HER3 on the basis of messenger RNA levels $(79,84)$. Finally, as HER4 testing is not routinely performed in clinical practice, there is no standard method for its assessment. However, the method most widely used in clinical trials is IHC (77).

\section{Agents Targeting the ErbB Family in Advanced Gastroesophageal Cancers}

Chemotherapy is the cornerstone of treatment for locally advanced and metastatic gastroesophageal cancer. Targeted therapies, in particular those directed against ErbB family receptors, have been investigated in the preclinical setting and some are currently undergoing assessment in clinical trials (Figure 1). However, unlike EGFR and HER2, relatively little is known about the role of HER3 and HER4 in gastric carcinogenesis or about the relationship between HER3 and HER4 and clinical pathological features, including overall survival. In particular, a better understanding of HER3 receptor functionality has unveiled the molecular cornerstones of its complex mechanism of action that are targetable through multiple pharmacological strategies, i.e., inhibition of ligand binding to the extracellular domain, receptor dimerization inhibition, and inhibition of the partner tyrosine kinase activity, all of which have the potential to benefit patients with HER3 overexpressing tumors. A lasting response was obtained in a phase I trial of anti-ERBB3 $\mathrm{mAb}$ therapy (GSK2849330) in individuals with advanced HER3-positive solid tumors (http://www.clinicaltrials.gov/show/ NCT01966445). Moreover, a phase III clinical trial (http://www. clinicaltrials.gov/show/NCT02134015) focusing on new HER3targeted antibodies was recently concluded and results are eagerly awaited.

A phase I clinical trial (http://www.clinicaltrials.gov/show/ NCT03552406) and a phase I/II clinical trial (http://www. clinicaltrials.gov/show/NCT02980341) focusing on new HER3targeted antibodies are currently recruiting patients with different solid tumors. Furthermore, 2 phase II clinical trials (http://www.clinicaltrials.gov/show/NCT03810872 and http:// www.clinicaltrials.gov/show/NCT02501603), both focusing on afatinib, are currently recruiting patients with different solid tumors. Afatinib is a promising novel small ErbB family blocker that covalently binds and irreversibly blocks signaling mediated by activated EGFR, HER2, and HER4 receptors, and also HER3 


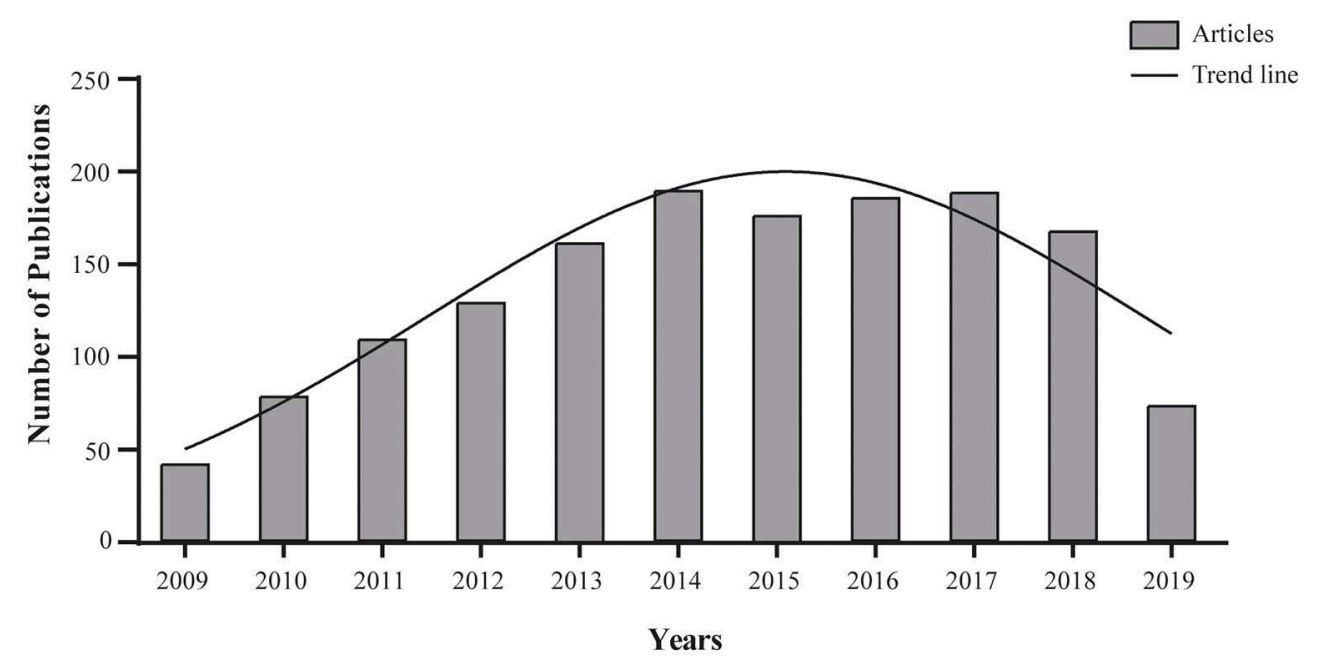

FIGURE 1 | Agents targeting the ErbB family. Search for article appearing in PUBMED database over the past 10 years using the mesh terms "Stomach Neoplasms" AND "ErbB Receptors" in the Advance research builder option.

transphosphorylation. Another phase II study (http://www. clinicaltrials.gov/show/NCT01953926) is currently exploring the efficacy and safety of neratinib, an irreversible panHER inhibitor in solid tumors with activating HER2, HER3 or EGFR mutations or with $E G F R$ gene amplification. Confirmation of their efficacy could pave the way for their use in gastric cancer as well (Table 3 ).

The following novel anti-ErbB inhibitors targeting EGFR and HER2 have been approved and are currently being developed for use in patients with gastroesophageal cancer.

\section{EGFR Inhibition}

The most common approaches to the inhibition of EGFR require the use of monoclonal antibodies. Cetuximab $\left(\right.$ Erbitux $\left.{ }^{\circledR}\right)$ is a chimeric monoclonal antibody (IgG1) that binds the extracellular domain of human EGFR, inducing its internalization, downregulation, and degradation. Furthermore, this antibody-receptor interaction competitively inhibits EGF binding, preventing receptor dimerization and blocking ligandinduced EGFR tyrosine kinase auto-phosphorylation and activation (85). Promising phase II data formed the basis for the phase III EXPAND trial (erbitux in combination with xeloda and cisplatin in advanced gastroesophageal cancer) in which 904 patients were randomized to receive cisplatin with capecitabine with or without cetuximab. However, a benefit in terms of progression-free (PFS) or overall survival (OS) was not observed in the cetuximab group (86).

RTOG 0436 is a randomized phase III trial comparing the efficacy of paclitaxel and cisplatin in combination with radiation therapy (daily $50.4 \mathrm{~Gy} / 1.8$ fractions) with or without cetuximab in patients with locally advanced esophageal cancer. The study is ongoing but currently not recruiting patients (https://clinicaltrials.gov/show/NCT00655876).

In contrast to their role in colorectal cancer, KRAS mutations have not proven to be a negative predictive biomarker of response to cetuximab in gastroesophageal cancer (87). Other biomarkers such as EGFR expression, copy number and phosporylation have also been evaluated, but sample size and the retrospective nature of the research have not led to meaningful conclusions $(88,89)$.

The other antibody used to inhibit EGFR is panitumumab (Vectibix ${ }^{\circledR}$ ), the first fully human IgG2 monoclonal antibody targeting EGFR. Its activity in gastric cancer was studied in a randomized open-label multicenter trial on the efficacy of epirubicin, oxaliplatin, and capecitabine (EOX) with or without panitumumab in untreated advanced gastroesophageal cancer (REAL-3 study) (http://www.clinicaltrials.gov/show/ NCT00824785). The results from this clinical trial did not show any benefit for the panitumumab-treated group, possibly due, in part, to reduced doses of chemotherapy administered in the combination arm, and the study was interrupted early (90).

In the ACOSOG Z4051 phase II study, patients with potentially resectable disease underwent neoadjuvant docetaxel, cisplatin, and panitumumab in combination with radiotherapy (91) (http://www.clinicaltrials.gov/show/NCT00757172). However, the activity of the multidrug combination was outweighed by the significant toxicity observed.

Nimotuzumab is a humanized therapeutic monoclonal antibody directed against EGFR. A phase II clinical trial is currently ongoing to assess the efficacy and safety of adding nimotuzumab to irinotecan after first-line treatment failure in patients with recurrent or metastatic EGFR-overexpressing gastric adenocarcinoma. In addition, as secondary aims, biomarkers for nimotuzumab efficacy in gastric cancer will be investigated (http://www.clinicaltrials.gov/show/NCT03400592).

Another phase II trial is ongoing to determine the safety and efficacy of varlitinib plus mFOLFOX6 for the treatment of gastric cancer (http://www.clinicaltrials.gov/show/NCT03130790). Varlitinib (also known as ASLAN001) is a small-molecule, adenosine triphosphate competitive inhibitor of EGFR, HER2 and HER4. EGFR inhibition by tyrosine kinase inhibitors (TKIs) such as iressa $\left(\right.$ Gefinitib ${ }^{\circledR}$ ) and tarceva (Erlotinib ${ }^{\circledR}$ ) (both oral 
TABLE 3 | Ongoing clinical investigations of HER3 targeted agents.

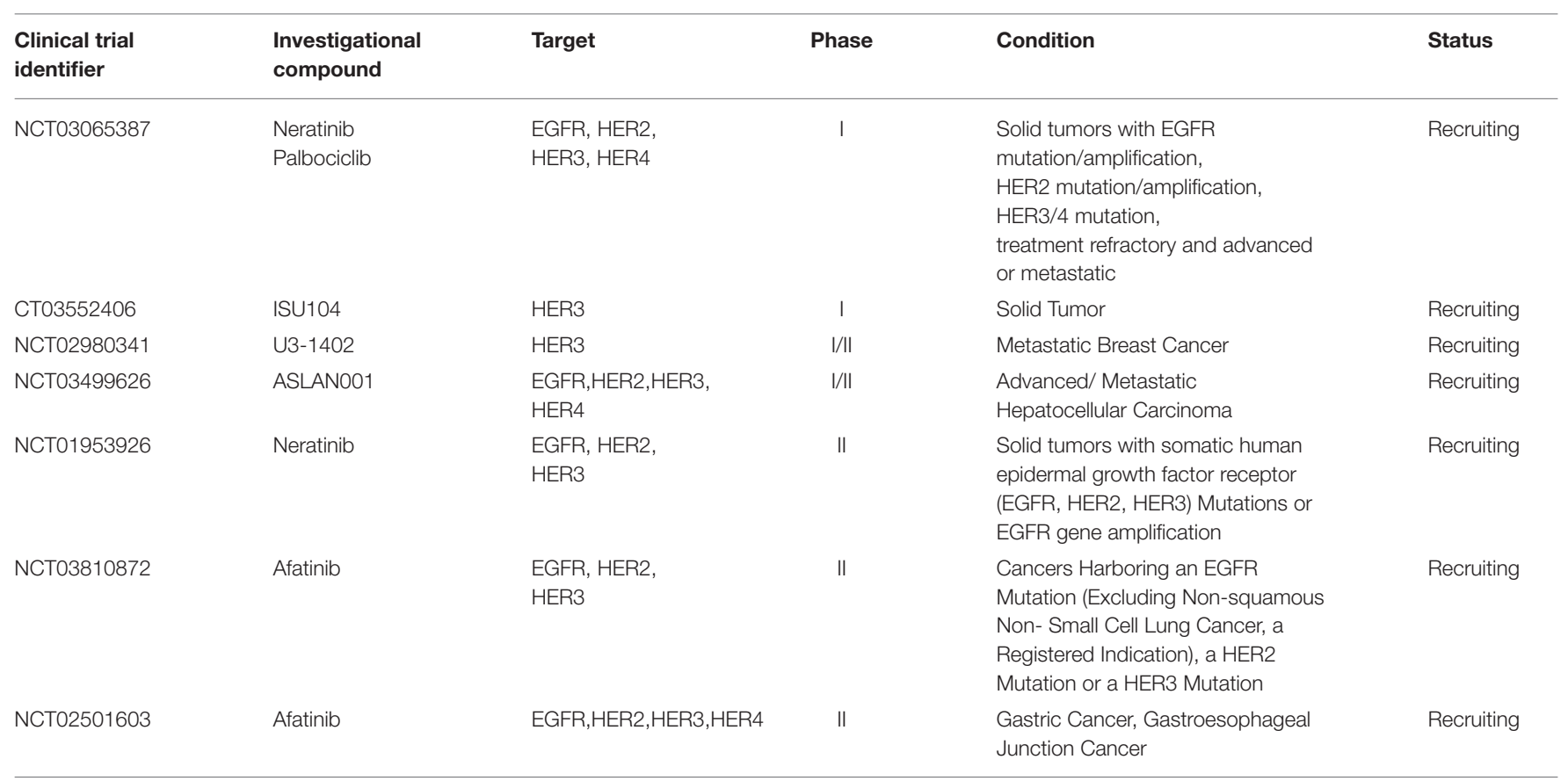

EGFR TKIs) has also been investigated in clinical trials on gastroesophageal cancer $(92,93)$.

\section{HER2 Inhibition}

On the basis of preclinical studies highlighting the significant activity of anti-HER2 therapies in both in vitro and in vivo gastric cancer models $(73,94,95)$, molecular drugs targeting HER2 have been widely studied in clinical trials on gastroesophageal cancer. Trastuzumab (Herceptin ${ }^{\circledR}$ ), a humanized monoclonal antibody that targets the extracellular binding domain of the HER2 receptor, was the first molecular targeted agent to be approved as standard treatment for gastric cancer $(29,96)$. It has been used in combination with cytotoxic chemotherapy in several clinical trials on gastric and gastroesophageal junction (GEJ) tumors (Table 4). The international, open-label phase III ToGA trial randomized patients with treatment-naive metastatic or locally advanced unresectable HER2-overexpressing gastric or GEJ adenocarcinoma to chemotherapy with trastuzumab or chemotherapy alone. HER2 overexpression was defined as 3+ staining by IHC or as positive FISH (29). The combination was generally well tolerated and a 2.7 month improvement in median OS was observed in the trastuzumab arm. Furthermore, response rate, time to progression and duration of response were significantly higher in the trastuzumab plus chemotherapy group.

The HELOISE trial was a randomized, multicenter, international phase IIIb study comparing the effectiveness and safety of 2 trastuzumab dosing regimens in combination with cisplatin/capecitabine in patients with metastatic gastric or GEJ cancer (http://www.clinicaltrials.gov/ show/NCT01450696). This study was interrupted for futility on the basis of results from the pre-planned interim analysis confirming the standard trastuzumab dose with chemotherapy as the standard-of-care for first-line treatment.

NCT01130337 is a sponsored phase II clinical trial designed to evaluate the disease-free survival rate of a combination of capecitabine and oxaliplatin with trastuzumab administered presurgery in patients with resectable gastric cancer. If a complete (R0) or microscopic residual tumor (R1) resection is obtained, patients receive a further two cycles of treatment. Trastuzumab is continued for a maximum of 1 year (available online: http:// clinicaltrials.gov/show/NCT01130337, results not yet posted).

Another sponsored phase II trial (TOXAG) has recently concluded proving that trastuzumab in combination with capecitabine, oxaliplatin and radiotherapy in the adjuvant setting for gastric or gastroesophageal junction adenocarcinoma is safe and tolerable (http://www.clinicaltrials.gov/show/ NCT01748773).

The Her-FLOT phase II study was designed to assess the efficacy of perioperative treatment based on trastuzumab in combination with FLOT (5FU, leucovorin, docetaxel, and oxaliplatin) in patients with HER2-positive locally advanced esophagogastric adenocarcinoma. Patients were administered trastuzumab with FLOT for four cycles prior to surgical resection followed by a further four cycles of chemotherapy with trastuzumab and nine additional cycles of trastuzumab alone. The aim of the study was to determine the rate of complete pathological response (http://www. clinicaltrials.gov/show/NCT01472029, results have yet to be posted).

RTOG 1010 is an ongoing phase III trial in which patients with locally advanced HER2-overexpressing esophageal or GEJ adenocarcinoma are randomized to receive combination treatment comprising radiotherapy, paclitaxel and carboplatin 
TABLE 4 | Ongoing clinical investigations of trastuzumab in gastric cancer.

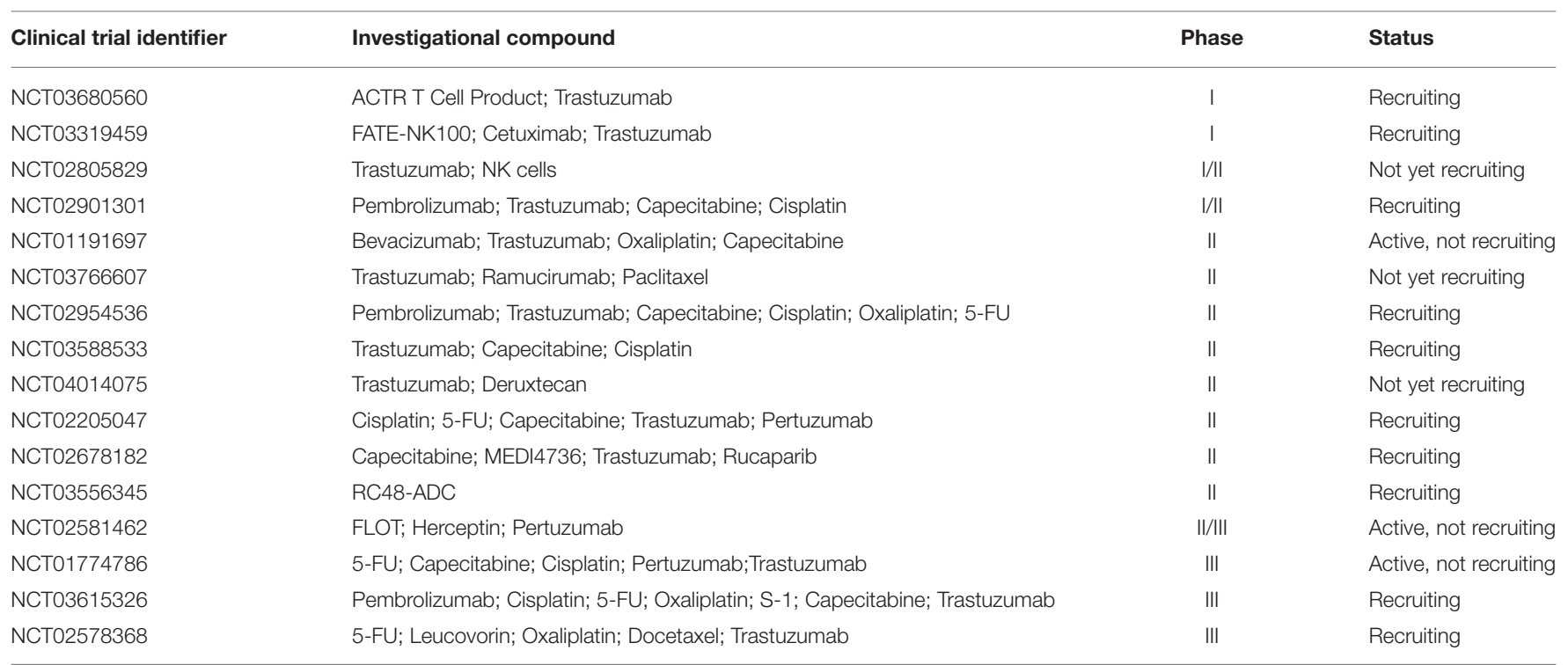

with or without trastuzumab prior to surgery (http:// clinicaltrials.gov/show/NCT01196390, study is active but currently not recruiting).

What is emerging from these studies is that a growing number of patients are experiencing resistance to trastuzumab (97). This has aroused great interest in second- generation HER2targeting agents such as pertuzumab (Perjeta $\left.{ }^{\circledR}\right)$. Pertuzumab binds a distinct site on the HER2 receptor (extracellular domain II) and disrupts HER2 dimerization, subsequently blocking downstream signaling (98). On the basis of pre-clinical studies on GEJ and of the effectiveness of the trastuzumab and pertuzumab combination in breast cancer (99), the JACOB phase III study was designed to investigate the efficacy and safety of pertuzumab in patients with HER2-positive metastatic or locally advanced unresectable GEJ or gastric cancer receiving first-line treatment with cisplatin, fluoropyrimidine (5-fluoruracil or capecitabine) and trastuzumab (https:// clinicaltrials.gov/show/NCT01774786, study is active but currently not recruiting).

Trastuzumab emtansine (TDM-1, KadCyla $\left.{ }^{\circledR}\right)$ is an antibodydrug conjugate of trastuzumab and DM1 (derivative of maytansine, a macrolide isolated from plants), a powerful microtubule inhibitor. In preclinical gastric cancer models, TDM-1 has demonstrated more aggressive antitumor activity than trastuzumab (100). A multicenter adaptive phase II/III of TDM-1 recruited patients with HER2-positive advanced gastric cancer in progression after first-line treatment (http://www. clinicaltrials.gov/show/NCT0164tab1939). In particular, patients with higher HER2 expression experienced a better treatment effect from TDM-1than those with lower HER2 expression (101).

Another approach to targeting HER2 is through inhibition

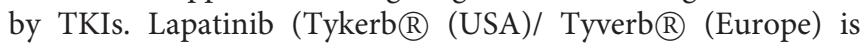
an oral small molecule dual TKI of EGFR and HER2 that inhibits the activation of $\mathrm{PI} 3 \mathrm{~K}$ and Ras pathways, which is activation, dependent on both receptors, leading to the downregulation of receptor tyrosine kinase phosphorylation in cancer cells. Lapatinib was evaluated in combination with standard chemotherapy in patients with HER2-positive gastric and GEJ adenocarcinomas (phase III LOGIC study, http:// www.clinicaltrials.gov/show/NCT00680901). This international multicenter trial investigated whether the addition of lapatinib to a capecitabine plus oxaliplatin regimen would extend the time to progression and OS. Although the trial did not meet its primary endpoint of improved OS, some subgroups (the Asian population and patients $<60$ years of age) were shown to benefit.

\section{CONCLUSIONS}

Several clinical trials using ErbB receptor family targeted treatment strategies have been carried out over the past few years, with varying results. Others are currently ongoing, as extensively described in the present review. The ToGA study paved the way for the use of ErbB receptor family targeted treatments, showing that trastuzumab improves survival in HER2-overexpressing advanced gastric cancer patients. This monoclonal antibody is now acknowledged as the standard first-line treatment in this subset of patients. The role of combinations of anti-ErbB drugs and cytotoxic therapies is currently being explored in the area of advanced gastric cancer in an effort to prevent or delay drug resistance. On the other hand, drugs targeting EGFR have not repeated the encouraging results seen in early clinical trials. Similarly, lapatinib, a dual TKI of EGFR, and HER2, failed to induce a benefit in patients enrolled onto two large phase III trials. The modest efficacy of these agents may be attributable to acquired resistance or to an mismatched combination with known cytotoxic agents. Furthermore, the clinical data collected to date on molecular drugs directly targeting HER3 suggest a limited potential of these agents for the treatment of gastric cancer. However, several clinical trials are still ongoing. 
It is now clear that results can only be improved by taking into account a number of important issues. First, the effects of the targeted therapy may be weakened because of differences in tumor histology (biomarkers), etiology (gastroesophageal reflux/Barret's esophagus, $H$. Pylori infection, alcohol and hot liquid intake, and smoking), and heterogeneity. Furthermore, tumor site (gastric, GEJ or esophagus) and population (Asia, America, Europe) should be considered background variables. For these reasons it is crucial to characterize tumors using established biomarkers, even though the diversity of molecular alterations acquired during malignant transformation, recurrence or metastasis makes it difficult to incorporate biomarkers into clinical trials. Finally, a better understanding of the complex interplay between growth factors and signaling pathway cross-talk would play a fundamental role in helping to identify individual patients who could benefit from ErbB receptor family targeted therapies.

\section{REFERENCES}

1. Bray F, Ferlay J, Soerjomataram I, Siegel Rl, Torre La, Jemal A. Global cancer statistics 2018: GLOBOCAN estimates of incidence and mortality worldwide for 36 cancers in 185 countries. CA Cancer J Clin. (2018) 68:394-424. doi: $10.3322 /$ caac. 21492

2. Ferlay J, Steliarova-Foucher E, Lortet-Tieulent J, Rosso S, Coebergh JW, Comber $\mathrm{H}$, et al. Cancer incidence and mortality patterns in Europe: estimates for 40 countries in 2012. Eur J Cancer. (2013) 49:1374-403. doi: 10.1016/j.ejca.2012.12.027

3. Forman D, Burley VJ. Gastric cancer: global pattern of the disease and an overview of environmental risk factors. Best Pract Res Clin Gastroenterol. (2006) 20:633-49. doi: 10.1016/j.bpg.2006.04.008

4. Bozzetti F, Marubini E, Bonfanti G, Miceli R, Piano C, Gennari L. Subtotal versus total gastrectomy for gastric cancer: five-year survival rates in a multicenter randomized Italian trial. Italian Gastrointestinal Tumor Study Group. Ann Surg. (1999) 230:170-8. doi: 10.1097/00000658-199908000-00006

5. Gouzi JL, Huguier M, Fagniez PL, Launois B, Flamant Y, Lacaine F, et al. Total versus subtotal gastrectomy for adenocarcinoma of the gastric antrum. A French prospective controlled study. Ann Surg. (1989) 209:162-6. doi: 10.1097/00000658-198902000-00005

6. Bennett C, Wang Y, Pan T. Endoscopic mucosal resection for early gastric cancer. Cochrane Database Syst Rev. (2009) 1:CD004276. doi: 10.1002/14651858.CD004276.pub3

7. Soetikno R, Kaltenbach T, Yeh R, Gotoda T. Endoscopic mucosal resection for early cancers of the upper gastrointestinal tract. J Clin Oncol. (2005) 23:4490-8. doi: 10.1200/JCO.2005.19.935

8. Cuschieri A, Fayers P, Fielding J, Craven J, Bancewicz J, Joypaul V, et al. Postoperative morbidity and mortality after D1 and D2 resections for gastric cancer: preliminary results of the MRC randomised controlled surgical trial. The Surgical Cooperative Group. Lancet. (1996) 347:995-9. doi: 10.1016/S0140-6736(96)90144-0

9. Songun I, Putter H, Kranenbarg EM, Sasako M, van de Velde CJ. Surgical treatment of gastric cancer: 15-year follow-up results of the randomised nationwide Dutch D1D2 trial. Lancet Oncol. (2010) 11:439-49. doi: 10.1016/S1470-2045(10)70070-X

10. Sasako M, Sano T, Yamamoto S, Kurokawa Y, Nashimoto A, Kurita A, et al. D2 lymphadenectomy alone or with para-aortic nodal dissection for gastric cancer. N Engl J Med. (2008) 359:453-62. doi: 10.1056/NEJMoa0707035

11. Woll E, Devries A, Eisterer W, Hejna M, Keil F, Stein H, et al. Chemotherapy in gastric cancer. Anticancer Res. (2008) 28:1213-9.

\section{CORE TIP}

Despite substantial improvements in targeted therapies for advanced gastric cancer, median overall survival remains $<12$ months. A better understanding of the molecular pathways associated with gastric cancer carcinogenesis could lead to new and better targeted treatment options. In particular, there is increasing evidence of the important role played by ErbB family members in driving gastric cancer growth. Our paper provides an overview of published and ongoing clinical studies evaluating the antitumor potential of molecular drugs targeting EGFR and HER2.

\section{AUTHOR CONTRIBUTIONS}

CA and AT reviewed the literature and co-drafted the manuscript. SP performed the literature research. All authors read and approved the final version of the paper.

12. Glimelius B, Ekstrom K, Hoffman K, Graf W, Sjoden PO, Haglund U, et al. Randomized comparison between chemotherapy plus best supportive care with best supportive care in advanced gastric cancer. Ann Oncol. (1997) 8:163-8. doi: 10.1023/A:1008243606668

13. Wagner AD, Unverzagt S, Grothe W, Kleber G, Grothey A, Haerting J, et al. Chemotherapy for advanced gastric cancer. Cochrane Database Syst Rev. (2010) 3:CD004064. doi: 10.1002/14651858.CD004064.pub3

14. Van Cutsem E, Moiseyenko VM, Tjulandin S, Majlis A, Constenla M, Boni C, et al. Phase III study of docetaxel and cisplatin plus fluorouracil compared with cisplatin and fluorouracil as first-line therapy for advanced gastric cancer: a report of the V325 Study Group. J Clin Oncol. (2006) 24:4991-7. doi: 10.1200/JCO.2006.06.8429

15. Waters JS, Norman A, Cunningham D, Scarffe JH, Webb A, Harper P, et al. Long-term survival after epirubicin, cisplatin and fluorouracil for gastric cancer: results of a randomized trial. Br J Cancer. (1999) 80:269-72. doi: 10.1038/sj.bjc. 6690350

16. Ajani JA, Moiseyenko VM, Tjulandin S, Majlis A, Constenla M, Boni C, et al. Clinical benefit with docetaxel plus fluorouracil and cisplatin compared with cisplatin and fluorouracil in a phase III trial of advanced gastric or gastroesophageal cancer adenocarcinoma: the V-325 Study Group. J Clin Oncol. (2007) 25:3205-9. doi: 10.1200/JCO.2006.10.4968

17. Cunningham D, Starling N, Rao S, Iveson T, Nicolson M, Coxon F, et al. Capecitabine and oxaliplatin for advanced esophagogastric cancer. $N$ Engl J Med. (2008) 358:36-46. doi: 10.1056/NEJMoa073149

18. Al-Batran SE, Hartmann JT, Probst S, Schmalenberg H, Hollerbach $S$, Hofheinz R, et al. Phase III trial in metastatic gastroesophageal adenocarcinoma with fluorouracil, leucovorin plus either oxaliplatin or cisplatin: a study of the Arbeitsgemeinschaft Internistische Onkologie. J Clin Oncol. (2008) 26:1435-42. doi: 10.1200/JCO.2007.13.9378

19. Montagnani F, Turrisi G, Marinozzi C, Aliberti C, Fiorentini G. Effectiveness and safety of oxaliplatin compared to cisplatin for advanced, unresectable gastric cancer: a systematic review and meta-analysis. Gastric Cancer. (2011) 14:50-5. doi: 10.1007/s10120-011-0007-7

20. Moertel CG, Childs DS Jr, Reitemeier RJ, Colby MY Jr, Holbrook MA. Combined 5-fluorouracil and supervoltage radiation therapy of locally unresectable gastrointestinal cancer. Lancet. (1969) 2:865-7. doi: 10.1016/S0140-6736(69)92326-5

21. Le Chevalier T, Smith FP, Harter WK, Schein PS. Chemotherapy and combined modality therapy for locally advanced and metastatic gastric carcinoma. Semin Oncol. (1985) 12:46-53.

22. Macdonald JS, Smalley SR, Benedetti J, Hundahl SA, Estes NC, Stemmermann GN, et al. Chemoradiotherapy after surgery compared 
with surgery alone for adenocarcinoma of the stomach or gastroesophageal junction. N Engl J Med. (2001) 345:725-30. doi: 10.1056/NEJMoa010187

23. Smalley SR, Benedetti JK, Haller DG, Hundahl SA, Estes NC, Ajani JA, et al. Updated analysis of SWOG-directed intergroup study 0116: a phase III trial of adjuvant radiochemotherapy vs. observation after curative gastric cancer resection. J Clin Oncol. (2012) 30:2327-33. doi: 10.1200/JCO.2011.3 6.7136

24. Stahl M, Walz MK, Stuschke M, Lehmann N, Meyer HJ, RieraKnorrenschild J, et al. Phase III comparison of preoperative chemotherapy compared with chemoradiotherapy in patients with locally advanced adenocarcinoma of the esophagogastric junction. J Clin Oncol. (2009) 27:851-6. doi: 10.1200/JCO.2008.17.0506

25. Sun P, Xiang JB, Chen ZY. Meta-analysis of adjuvant chemotherapy after radical surgery for advanced gastric cancer. Br J Surg. (2009) 96:26-33. doi: 10.1002/bjs.6408

26. GASTRIC (Global Advanced/Adjuvant Stomach Tumor Research International Collaboration) Group, Paoletti X, Oba K, Burzykowski T, Michiels S, Ohashi Y, et al. Benefit of adjuvant chemotherapy for resectable gastric cancer: a meta-analysis. JAMA. (2010) 303:1729-37. doi: 10.1001/jama.2010.534

27. Cunningham D, Allum WH, Stenning SP, Thompson JN, Van de Velde CJ, Nicolson $\mathrm{M}$, et al. Perioperative chemotherapy versus surgery alone for resectable gastroesophageal cancer. N Engl J Med. (2006) 355:11-20. doi: 10.1056/NEJMoa055531

28. Sasako M, Sakuramoto S, Katai H, Kinoshita T, Furukawa H, Yamaguchi $\mathrm{T}$, et al. Five-year outcomes of a randomized phase III trial comparing adjuvant chemotherapy with S-1 versus surgery alone in stage II or III gastric cancer. J Clin Oncol. (2011) 29:4387-93. doi: 10.1200/JCO.2011.3 6.5908

29. Bang YJ, Van Cutsem E, Feyereislova A, Chung HC, Shen L, Sawaki A, et al. Trastuzumab in combination with chemotherapy versus chemotherapy alone for treatment of HER2-positive advanced gastric or gastro-oesophageal junction cancer (ToGA): a phase 3, open-label, randomised controlled trial. Lancet. (2010) 376:687-97. doi: 10.1016/S0140-6736(10)61121-X

30. Nagatsuma AK, Aizawa M, Kuwata T, Doi T, Ohtsu A, Fujii H, et al. Expression profiles of HER2, EGFR, MET and FGFR2 in a large cohort of patients with gastric adenocarcinoma. Gastric Cancer. (2015) 18:227-38. doi: 10.1007/s10120-014-0360-4

31. Yarden Y, Sliwkowski MX. Untangling the ErbB signalling network. Nat Rev Mol Cell Biol. (2001) 2:127-37. doi: 10.1038/35052073

32. Cohen S. The epidermal growth factor (EGF). Cancer. (1983) 51:178791. doi: 10.1002/1097-0142(19830515)51:10 < 1787::AID-CNCR2820511004 > 3.0.CO;2-A

33. Thompson DM, Gill GN. The EGF receptor: structure, regulation and potential role in malignancy. Cancer Surv. (1985) 4:767-88.

34. Riely GJ, Politi KA, Miller VA, Pao W. Update on epidermal growth factor receptor mutations in non-small cell lung cancer. Clin Cancer Res. (2006) 12:7232-41. doi: 10.1158/1078-0432.CCR-06-0658

35. Witton CJ, Reeves JR, Going JJ, Cooke TG, Bartlett JM. Expression of the HER1-4 family of receptor tyrosine kinases in breast cancer. J Pathol. (2003) 200:290-7. doi: 10.1002/path.1370

36. Kapitanovic S, Radosevic S, Slade N, Kapitanovic M, Andelinovic S, Ferencic $\mathrm{Z}$, et al. Expression of erbB-3 protein in colorectal adenocarcinoma: correlation with poor survival. J Cancer Res Clin Oncol. (2000) 126:205-11.. doi: $10.1007 / \mathrm{s} 004320050034$

37. Wei Q, Sheng L, Shui Y, Hu Q, Nordgren H, Carlsson J. EGFR, HER2, and HER3 expression in laryngeal primary tumors and corresponding metastases. Ann Surg Oncol. (2008) 15:1193-201. doi: 10.1245/s10434-007-9771-3

38. Wei Q, Chen L, Sheng L, Nordgren H, Wester K, Carlsson J. EGFR, HER2 and HER3 expression in esophageal primary tumours and corresponding metastases. Int J Oncol. (2007) 31:493-9. doi: 10.3892/ijo.31.3.493

39. Tanner B, Hasenclever D, Stern K, Schormann W, Bezler M, Hermes M, et al. ErbB-3 predicts survival in ovarian cancer. J Clin Oncol. (2006) 24:4317-23. doi: 10.1200/JCO.2005.04.8397

40. Koumakpayi IH, Diallo JS, Le Page C, Lessard L, Gleave M, Begin LR, et al. Expression and nuclear localization of ErbB3 in prostate cancer. Clin Cancer Res. (2006) 12:2730-7. doi: 10.1158/1078-0432.CCR-05-2242
41. Reschke M, Mihic-Probst D, van der Horst EH, Knyazev P, Wild PJ, Hutterer $\mathrm{M}$, et al. HER3 is a determinant for poor prognosis in melanoma. Clin Cancer Res. (2008) 14:5188-97. doi: 10.1158/1078-0432.CCR-08-0186

42. Yarden Y, Pines G. The ERBB network: at last, cancer therapy meets systems biology. Nat Rev Cancer. (2012) 12:553-63. doi: 10.1038/nrc3309

43. Seshacharyulu P, Ponnusamy MP, Haridas D, Jain M, Ganti AK, Batra SK. Targeting the EGFR signaling pathway in cancer therapy. Expert Opin Ther Targets. (2012) 16:15-31. doi: 10.1517/14728222.2011.648617

44. Cho HS, Mason K, Ramyar KX, Stanley AM, Gabelli SB, Denney DW Jr, et al. Structure of the extracellular region of HER2 alone and in complex with the Herceptin Fab. Nature. (2003) 421:756-60. doi: 10.1038/nature01392

45. Garrett TP, McKern NM, Lou M, Elleman TC, Adams TE, Lovrecz GO, et al. The crystal structure of a truncated ErbB2 ectodomain reveals an active conformation, poised to interact with other ErbB receptors. Mol Cell. (2003) 11:495-505. doi: 10.1016/S1097-2765(03)00048-0

46. Olayioye MA, Neve RM, Lane HA, Hynes NE. The ErbB signaling network: receptor heterodimerization in development and cancer. EMBO J. (2000) 19:3159-67. doi: 10.1093/emboj/19.13.3159

47. Normanno N, Bianco C, Strizzi L, Mancino M, Maiello MR, De Luca A, et al. The ErbB receptors and their ligands in cancer: an overview. Curr Drug Targets. (2005) 6:243-57. doi: 10.2174/1389450053765879

48. Shi F, Telesco SE, Liu Y, Radhakrishnan R, Lemmon MA. ErbB3/HER3 intracellular domain is competent to bind ATP and catalyze autophosphorylation. Proc Natl Acad Sci USA. (2010) 107:7692-7. doi: 10.1073/pnas.1002753107

49. Fedi P, Pierce JH, di Fiore PP, Kraus MH. Efficient coupling with phosphatidylinositol 3-kinase, but not phospholipase C gamma or GTPase-activating protein, distinguishes ErbB-3 signaling from that of other ErbB/EGFR family members. Mol Cell Biol. (1994) 14:492-500. doi: 10.1128/MCB.14.1.492

50. Soltoff SP, Carraway KL III, Prigent SA, Gullick WG, Cantley LC. ErbB3 is involved in activation of phosphatidylinositol 3-kinase by epidermal growth factor. Mol Cell Biol. (1994) 14:3550-8. doi: 10.1128/MCB.14.6.3550

51. Prigent SA, Gullick WJ. Identification of c-erbB-3 binding sites for phosphatidylinositol 3'-kinase and SHC using an EGF receptor/c-erbB-3 chimera. EMBO J. (1994) 13:2831-41. doi: 10.1002/j.1460-2075.1994.tb06577.x

52. Vaught DB, Stanford JC, Young C, Hicks DJ, Wheeler F, Rinehart C, et al. HER3 is required for HER2-induced preneoplastic changes to the breast epithelium and tumor formation. Cancer Res. (2012) 72:2672-82. doi: 10.1158/0008-5472.CAN-11-3594

53. Holbro T, Beerli RR, Maurer F, Koziczak M, Barbas CF,3rd, Hynes NE. The ErbB2/ErbB3 heterodimer functions as an oncogenic unit: ErbB2 requires ErbB3 to drive breast tumor cell proliferation. Proc Natl Acad Sci USA. (2003) 100:8933-8. doi: 10.1073/pnas. 1537685100

54. Engelman JA, Zejnullahu K, Mitsudomi T, Song Y, Hyland C, Park JO, et al. MET amplification leads to gefitinib resistance in lung cancer by activating ERBB3 signaling. Science. (2007) 316:1039-43. doi: 10.1126/science.1141478

55. Choi BK, Fan X, Deng H, Zhang N, An Z. ERBB3 (HER3) is a key sensor in the regulation of ERBB-mediated signaling in both low and high ERBB2 (HER2) expressing cancer cells. Cancer Med. (2012) 1:28-38. doi: $10.1002 / \mathrm{cam} 4.10$

56. Sartor CI, Zhou H, Kozlowska E, Guttridge K, Kawata E, Caskey L, et al. Her4 mediates ligand-dependent antiproliferative and differentiation responses in human breast cancer cells. Mol Cell Biol. (2001) 21:4265-75. doi: 10.1128/MCB.21.13.4265-4275.2001

57. Naresh A, Long W, Vidal GA, Wimley WC, Marrero L, Sartor CI, et al. The ERBB4/HER4 intracellular domain 4ICD is a BH3-only protein promoting apoptosis of breast cancer cells. Cancer Res. (2006) 66:6412-20. doi: 10.1158/0008-5472.CAN-05-2368

58. Barnes NL, Khavari S, Boland GP, Cramer A, Knox WF, Bundred NJ. Absence of HER4 expression predicts recurrence of ductal carcinoma in situ of the breast. Clin Cancer Res. (2005) 11:2163-8. doi: 10.1158/1078-0432.CCR-04-1633

59. Kainulainen V, Sundvall M, Maatta JA, Santiestevan E, Klagsbrun M, Elenius K. A natural ErbB4 isoform that does not activate phosphoinositide 3-kinase mediates proliferation but not survival or chemotaxis. J Biol Chem. (2000) 275:8641-9. doi: $10.1074 / \mathrm{jbc} .275 .12 .8641$ 
60. Rio C, Buxbaum JD, Peschon JJ, Corfas G. Tumor necrosis factor-alphaconverting enzyme is required for cleavage of erbB4/HER4. J Biol Chem. (2000) 275:10379-87. doi: 10.1074/jbc.275.14.10379

61. Ni CY, Murphy MP, Golde TE, Carpenter G. gamma -Secretase cleavage and nuclear localization of ErbB-4 receptor tyrosine kinase. Science. (2001) 294:2179-81. doi: 10.1126/science.1065412

62. Jones FE. HER4 intracellular domain (4ICD) activity in the developing mammary gland and breast cancer. J Mammary Gland Biol Neoplasia. (2008) 13:247-58. doi: 10.1007/s10911-008-9076-6

63. Zhu Y, Sullivan LL, Nair SS, Williams CC, Pandey AK, Marrero L, et al. Coregulation of estrogen receptor by ERBB4/HER4 establishes a growthpromoting autocrine signal in breast tumor cells. Cancer Res. (2006) 66:7991-8. doi: 10.1158/0008-5472.CAN-05-4397

64. Dulak AM, Schumacher SE, van Lieshout J, Imamura Y, Fox C, Shim B, et al. Gastrointestinal adenocarcinomas of the esophagus, stomach, and colon exhibit distinct patterns of genome instability and oncogenesis. Cancer Res. (2012) 72:4383-93. doi: 10.1158/0008-5472.CAN-11-3893

65. Kim MA, Lee HS, Lee HE, Jeon YK, Yang HK, Kim WH. EGFR in gastric carcinomas: prognostic significance of protein overexpression and high gene copy number. Histopathology. (2008) 52:738-46. doi: 10.1111/j.1365-2559.2008.03021.x

66. Kandel C, Leclair F, Bou-Hanna C, Laboisse CL, Mosnier JF. Association of HER1 amplification with poor prognosis in well differentiated gastric carcinomas. J Clin Pathol. (2014) 67:307-12. doi: 10.1136/jclinpath-2013-201726

67. Chen C, Yang JM, Hu TT, Xu TJ, Yan G, Hu SL, et al. Prognostic role of human epidermal growth factor receptor in gastric cancer: a systematic review and meta-analysis. Arch Med Res. (2013) 44:380-9. doi: 10.1016/j.arcmed.2013.07.001

68. Aydin K, Okutur SK, Bozkurt M, Turkmen I, Namal E, Pilanci K, et al. Effect of epidermal growth factor receptor status on the outcomes of patients with metastatic gastric cancer: a pilot study. Oncol Lett. (2014) 7:255-9. doi: 10.3892/ol.2013.1662

69. Hong L, Han Y, Yang J, Zhang H, Jin Y, Brain L, et al. Prognostic value of epidermal growth factor receptor in patients with gastric cancer: a metaanalysis. Gene. (2013) 529:69-72. doi: 10.1016/j.gene.2013.07.106

70. Boku N. HER2-positive gastric cancer. Gastric Cancer. (2014) 17:1-12. doi: $10.1007 / \mathrm{s} 10120-013-0252-\mathrm{z}$

71. Gravalos C, Jimeno A. HER2 in gastric cancer: a new prognostic factor and a novel therapeutic target. Ann Oncol. (2008) 19:1523-9. doi: 10.1093/annonc/mdn169

72. Dang HZ, Yu Y, Jiao SC. Prognosis of HER2 over-expressing gastric cancer patients with liver metastasis. World J Gastroenterol. (2012) 18:2402-7. doi: 10.3748/wjg.v18.i19.2402

73. Tanner M, Hollmen M, Junttila TT, Kapanen AI, Tommola S, Soini $\mathrm{Y}$, et al. Amplification of HER-2 in gastric carcinoma: association with Topoisomerase IIalpha gene amplification, intestinal type, poor prognosis and sensitivity to trastuzumab. Ann Oncol. (2005) 16:273-8. doi: 10.1093/annonc/mdi064

74. Janjigian YY, Werner D, Pauligk C, Steinmetz K, Kelsen DP, Jager E, et al. Prognosis of metastatic gastric and gastroesophageal junction cancer by HER2 status: a European and USA International collaborative analysis. Ann Oncol. (2012) 23:2656-62. doi: 10.1093/annonc/mds104

75. Gomez-Martin C, Garralda E, Echarri MJ, Ballesteros A, Arcediano A, Rodriguez-Peralto JL, et al. HER2/neu testing for anti-HER2-based therapies in patients with unresectable and/or metastatic gastric cancer. J Clin Pathol. (2012) 65:751-7. doi: 10.1136/jclinpath-2012-200774

76. Moelans CB, Milne AN, Morsink FH, Offerhaus GJ, van Diest PJ. Low frequency of HER2 amplification and overexpression in early onset gastric cancer. Cell Oncol. (2011) 34:89-95. doi: 10.1007/s13402-011-0021-0

77. He XX, Ding L, Lin Y, Shu M, Wen JM, Xue L. Protein expression of HER2, 3, 4 in gastric cancer: correlation with clinical features and survival. J Clin Pathol. (2015) 68:374-80. doi: 10.1136/jclinpath-2014-202657

78. Hayashi M, Inokuchi M, Takagi Y, Yamada H, Kojima K, Kumagai $\mathrm{J}$, et al. High expression of HER3 is associated with a decreased survival in gastric cancer. Clin Cancer Res. (2008) 14:7843-9. doi: 10.1158/1078-0432.CCR-08-1064
79. Abrahao-Machado LF, Scapulatempo-Neto C. HER2 testing in gastric cancer: an update. World J Gastroenterol. (2016) 22:4619-25. doi: 10.3748/wjg.v22.i19.4619

80. Jacome AA, Wohnrath DR, Scapulatempo Neto C, Carneseca EC, Serrano SV, Viana LS, et al. Prognostic value of epidermal growth factor receptors in gastric cancer: a survival analysis by Weibull model incorporating long-term survivors. Gastric Cancer. (2014) 17:76-86. doi: 10.1007/s10120-013-0236-Z

81. Atmaca A, Werner D, Pauligk C, Steinmetz K, Wirtz R, Altmannsberger $\mathrm{HM}$, et al. The prognostic impact of epidermal growth factor receptor in patients with metastatic gastric cancer. BMC Cancer. (2012) 12:524. doi: 10.1186/1471-2407-12-524

82. Hofmann M, Stoss O, Shi D, Buttner R, van de Vijver M, Kim W, et al. Assessment of a HER2 scoring system for gastric cancer: results from a validation study. Histopathology. (2008) 52:797-805. doi: 10.1111/j.1365-2559.2008.03028.x

83. Albarello L, Pecciarini L, Doglioni C. HER2 testing in gastric cancer. $A d v$ Anat Pathol. (2011) 18:53-9. doi: 10.1097/PAP.0b013e3182026d72

84. Tang D, Liu CY, Shen D, Fan S, Su X, Ye P, et al. Assessment and prognostic analysis of EGFR, HER2, and HER3 protein expression in surgically resected gastric adenocarcinomas. Onco Targets Ther. (2014) 8:714. doi: 10.2147/OTT.S70922

85. Martinelli E, De Palma R, Orditura M, De Vita F, Ciardiello F. Antiepidermal growth factor receptor monoclonal antibodies in cancer therapy. Clin Exp Immunol. (2009) 158:1-9. doi: 10.1111/j.1365-2249.2009.03992.x

86. Lordick F, Kang YK, Chung HC, Salman P, Oh SC, Bodoky G, et al. Capecitabine and cisplatin with or without cetuximab for patients with previously untreated advanced gastric cancer (EXPAND): a randomised, open-label phase 3 trial. Lancet Oncol. (2013) 14:490-9. doi: 10.1016/S1470-2045(13)70102-5

87. Park SR, Kook MC, Choi IJ, Kim CG, Lee JY, Cho SJ, et al. Predictive factors for the efficacy of cetuximab plus chemotherapy as salvage therapy in metastatic gastric cancer patients. Cancer Chemother Pharmacol. (2010) 65:579-87. doi: 10.1007/s00280-009-1067-9

88. Luber B, Deplazes J, Keller G, Walch A, Rauser S, Eichmann M, et al. Biomarker analysis of cetuximab plus oxaliplatin/leucovorin/5-fluorouracil in first-line metastatic gastric and oesophago-gastric junction cancer: results from a phase II trial of the Arbeitsgemeinschaft Internistische Onkologie (AIO). BMC Cancer. (2011) 11:509. doi: 10.1186/1471-2407-11-509

89. Lordick F, Luber B, Lorenzen S, Hegewisch-Becker S, Folprecht G, Woll E, et al. Cetuximab plus oxaliplatin/leucovorin/5-fluorouracil in first-line metastatic gastric cancer: a phase II study of the Arbeitsgemeinschaft Internistische Onkologie (AIO). Br J Cancer. (2010) 102:500-5. doi: $10.1038 /$ sj.bjc. 6605521

90. Waddell T, Chau I, Cunningham D, Gonzalez D, Okines AF, Okines C, et al. Epirubicin, oxaliplatin, and capecitabine with or without panitumumab for patients with previously untreated advanced oesophagogastric cancer (REAL3): a randomised, open-label phase 3 trial. Lancet Oncol. (2013) 14:481-9. doi: 10.1016/S1470-2045(13)70096-2

91. Lockhart AC, Reed CE, Decker PA, Meyers BF, Ferguson MK, Oeltjen $\mathrm{AR}$, et al. Phase II study of neoadjuvant therapy with docetaxel, cisplatin, panitumumab, and radiation therapy followed by surgery in patients with locally advanced adenocarcinoma of the distal esophagus (ACOSOG Z4051). Ann Oncol. (2014) 25:1039-44. doi: 10.1093/annonc/mdu091

92. Rojo F, Tabernero J, Albanell J, Van Cutsem E, Ohtsu A, Doi T, et al. Pharmacodynamic studies of gefitinib in tumor biopsy specimens from patients with advanced gastric carcinoma. J Clin Oncol. (2006) 24:4309-16. doi: 10.1200/JCO.2005.04.2424

93. Dragovich T, McCoy S, Fenoglio-Preiser CM, Wang J, Benedetti JK, Baker $\mathrm{AF}$, et al. Phase II trial of erlotinib in gastroesophageal junction and gastric adenocarcinomas: SWOG 0127. J Clin Oncol. (2006) 24:4922-7. doi: 10.1200/JCO.2006.07.1316

94. Matsui Y, Inomata M, Tojigamori M, Sonoda K, Shiraishi N, Kitano S. Suppression of tumor growth in human gastric cancer with HER2 overexpression by an anti-HER2 antibody in a murine model. Int J Oncol. (2005) 27:681-5. doi: 10.3892/ijo.27.3.681

95. Arienti C, Zanoni M, Pignatta S, Del Rio A, Carloni S, Tebaldi $M$, et al. Preclinical evidence of multiple mechanisms underlying 
trastuzumab resistance in gastric cancer. Oncotarget. (2016) 7:18424-39. doi: 10.18632/oncotarget.7575

96. Roukos DH. Targeting gastric cancer with trastuzumab: new clinical practice and innovative developments to overcome resistance. Ann Surg Oncol. (2010) 17:14-7. doi: 10.1245/s10434-009-0766-0

97. Shimoyama S. Unraveling trastuzumab and lapatinib inefficiency in gastric cancer: future steps (Review). Mol Clin Oncol. (2014) 2:175-81. doi: $10.3892 / \mathrm{mco} .2013 .218$

98. Agus DB, Akita RW, Fox WD, Lewis GD, Higgins B, Pisacane $\mathrm{PI}$, et al. Targeting ligand-activated ErbB2 signaling inhibits breast and prostate tumor growth. Cancer Cell. (2002) 2:127-37. doi: 10.1016/S1535-6108(02)00097-1

99. Baselga J, Cortes J, Kim SB, Im SA, Hegg R, Im YH, et al. Pertuzumab plus trastuzumab plus docetaxel for metastatic breast cancer. N Engl J Med. (2012) 366:109-19. doi: 10.1056/NEJMoa1113216

100. Barok M, Tanner M, Koninki K, Isola J. Trastuzumab-DM1 is highly effective in preclinical models of HER2-positive gastric cancer. Cancer Lett. (2011) 306:171-9. doi: 10.1016/j.canlet.2011.03.002
101. Shah MA, Kang YK, Thuss-Patience PC, Ohtsu A, Ajani JA, Van Cutsem E, et al. Biomarker analysis of the GATSBY study of trastuzumab emtansine versus a taxane in previously treated HER2-positive advanced gastric/gastroesophageal junction cancer. Gastric Cancer. (2019) 22:803-16. doi: 10.1007/s10120-018-0 0923-7

Conflict of Interest: The authors declare that the research was conducted in the absence of any commercial or financial relationships that could be construed as a potential conflict of interest.

Copyright (c) 2019 Arienti, Pignatta and Tesei. This is an open-access article distributed under the terms of the Creative Commons Attribution License (CC BY). The use, distribution or reproduction in other forums is permitted, provided the original author(s) and the copyright owner(s) are credited and that the original publication in this journal is cited, in accordance with accepted academic practice. No use, distribution or reproduction is permitted which does not comply with these terms. 